\title{
Doença reumática: negligenciada, mas ainda presente e mortal
}

\author{
Rheumatic disease: neglected but still \\ present and deadlly
}

Guilherme Sobreira Spina $^{1}$

Spina GS. Doença reumática: negligenciada, mas ainda presente e mortal. Rev Med (São Paulo). 2008 abr.-jun.;87(2):128-41.

RESUMO: A Febre Reumática é uma doença freqüente e que inflige sérias conseqüências a um numeroso grupo de pacientes. É causa freqüente de cirurgia cardíaca em nosso meio. Sua fisiopatologia é complexa e as primeiras manifestações são extremamente variáveis, fazendo com que seja de difícil diagnóstico. $O$ artigo faz um resumo da fisiopatologia atual, quadro clínico e tratamentos mais indicados para pacientes com Febre Reumática. Deve ser enfatizada a profilaxia, especialmente a profilaxia primária, que impede o desenvolvimento da doença.

DESCRITORES: Febre reumática/diagnóstico. Febre reumática/fisiopatologia. Cardiopatia reumática/complicações. Cardiopatia reumática/mortalidade.

\section{INTRODUÇÃO}

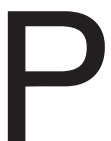

ara muitos, causa surpresa falar em Febre Reumática em pleno século XXI. A ausência de referências a esta doença na literatura estrangeira, que geralmente serve como referência para a maioria dos médicos, faz com que pensem que é coisa do passado, uma curiosidade. Para o não-especialista, falar em Febre Reumática é hoje tão relevante quanto falar sobre fisiopatologia da varíola.
Nunca esquecerei o professor de microbiologia no meu $3^{\circ}$ ano da faculdade, quando já freqüentava a Liga de Combate à Febre Reumática comentar "nossa, ainda vocês tratam pacientes com FR na Liga... acho que vocês só devem acompanhar idosos, pois não existe mais Febre Reumática". Marcou-me sua expressão de espanto e incredulidade, quando o informei, após o final da aula, que na semana anterior havia atendido dois adolescentes com insuficiência cardíaca grave decorrente de cardite reumática aguda. Desde então observo as dificuldades de estudar

\footnotetext{
1. Orientador da Liga de Combate à Febre Reumática do HC-FMUSP. Doutor em Cardiologia pela FMUSP. Médico Assistente da Unidade Clínica de Valvopatia do InCor - HCFMUSP.

Endereço para correspondência: Instituto do Coração da Faculdade de Medicina da Universidade de São Paulo. Av. Dr. Enéas de Carvalho Aguiqr, 44. São Paulo, SP.
} 
Spina GS. Doença reumática: negligenciada, mas ainda presente e mortal.

uma doença que aflige apenas paises pobres, que raramente merece atenção da literatura médica.

A prevalência de Febre Reumática (FR) e Cardiopatia Reumática Crônica em uma determinada comunidade são reflexos do nível de cuidados preventivos primários ${ }^{1}$. Nos países desenvolvidos a doença tornou-se rara, enquanto que em países pobres, como o Brasil, a Cardiopatia Reumática Crônica permanece como a maior causa de doença cardíaca entre crianças e adultos jovens.

A situação se agrava ainda mais quando consideramos que a FR é doença de diagnóstico clínico, não podendo, na maioria das vezes, ser confirmada por exames laboratoriais. O diagnóstico puramente clínico traz dificuldades e angústias para os médicos, e leva frequentemente a diagnósticos errôneos de FR e principalmente subdiagnóstico de pacientes com cardiopatia reumática grave.

\section{As dificuldades em analisar o impacto da doença}

Ao analisarmos então o impacto da Febre Reumática nos deparamos com dois tipos de dados: o impacto da Febre Reumática Aguda e o impacto das seqüelas valvares reumáticas.

Infelizmente, nenhum destes dados tem o poder de revelar o real impacto da Febre Reumática: os dados sobre cirurgias cardíacas relacionadas à valvopatia reumática demonstram como a doença esteve ativa nas últimas décadas: do surto reumático inicial até seqüelas valvares graves que determinam insuficiência cardíaca podem se passar de uma a três décadas. Um paciente que necessita cirurgia cardíaca hoje reflete um surto de Febre Reumática 10 ou 20 anos atrás, que muito provavelmente não foi diagnosticado corretamente ou, como é a maioria dos casos, foi assintomático.

Os números relativos a internações por Febre Reumática aguda são ainda mais traiçoeiros: estudos realizados na Liga de Combate à Febre Reumática do HC-FMUSP revelam que apenas cerca de 2 a $3 \%$ dos pacientes com Febre Reumática aguda necessitam de internação: a maioria pode ser mantida em tratamento domiciliar, com seguimento ambulatorial cuidadoso e freqüente. Ao analisarmos números de internações decorrentes de Febre Reumática, para ter uma estimativa mais próxima da realidade deveríamos multiplicar esses números por 80 ou 90. Para cada caso internado, temos uma multidão de pacientes com Febre Reumática aguda, assintomática ou não-diagnosticada, muitos dos quais só procurarão assistência médica depois de uma ou duas décadas, quando iniciarem sintomas de insuficiência cardíaca decorrentes de suas valvopatias.

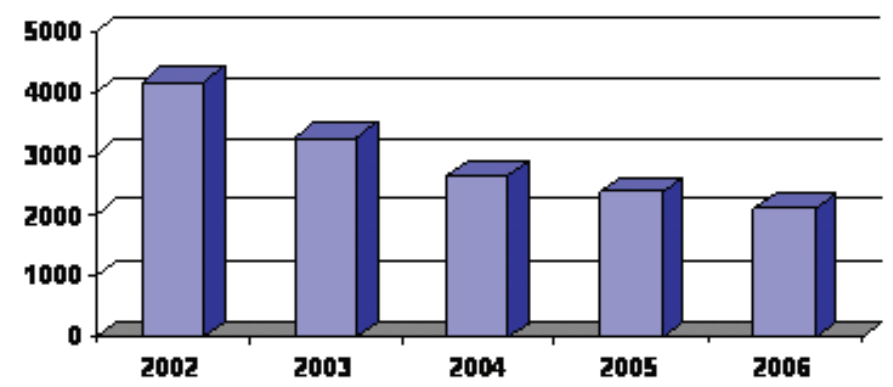

Fonte: Ministério da Saúde - Sistema de informações hospitalares do SUS (SIH/SUS). Gráfico 1. Número de casos internados por Febre Reumática Aguda no Brasil

Pensando desta forma, ainda há um número muito alto de internações decorrentes de Febre Reumática. Ainda mais se pensarmos que em uma população apenas cerca de 3\% dos indivíduos são predispostos a desenvolver Febre Reumática após episódio de amigdalite estreptocócica. Ou seja, dos 188.000.000 de habitantes no Brasil (segundo o IBGE), aproximadamente 5.640.000 tem risco de desenvolver Febre Reumática após amigdalite esteptocócica. Se cerca de 2500 pacientes são internados ao ano com diagnóstico de FR, e estes perfazem $2 \%$ da população de pacientes com FR aguda, estimamos que 125.000 pacientes no Brasil tenham FR aguda todos os anos.

Em geral, 30\% dos pacientes com FR aguda apresentam acometimento cardíaco (37500 pacientes por ano, aproximadamente). Se imaginarmos que $30 \%$ destes irão desenvolver seqüelas valvares graves, temos um total de pelo menos 11200 pacientes com possível seqüela grave decorrente de Febre Reumática.

E pior, esta população de pacientes irá 
demorar de 10 a 30 anos para procurar atenção médica, quando muitos deles estarão com seqüelas cardíacas graves de Febre Reumática, muitos com necessidade de cirurgia cardíaca. As estatísticas da Febre Reumática aguda apontam para um futuro sombrio, no qual as seqüelas reumáticas ainda serão freqüentes, dificilmente desaparecendo da prática médica neste século.

Estatísticas internacionais indicam que o Brasil ainda é dos países com maior incidência de Febre Reumática. Os dados que embasam estas estatísticas são resultado de pequenos levantamentos estatísticos,em geral em estados do Sul e Sudeste. Há motivo para acreditarmos que o valor real de incidência é ainda maior.

Este é um valor extremamente elevado, considerando que esta, das doenças cardiológicas, é com certeza a que tem maior facilidade na prevenção².

\section{O estreptococo}

A correlação entre FR aguda e amigdalites estreptocócicas foi postulada no início do século, e mais tarde demonstrada em estudos epidemiológicos nas décadas de 30 e 40. Os estudos de Rebecca Lancefield permitiram a classificação do estreptococo como grupo $A$, e a definição de sua composição celular.

O estreptococo do grupo A, ou Streptococcus pyogenes contém na camada mais externa as proteínas $\mathrm{M}, \mathrm{T}$ e $\mathrm{R}$ e o ácido lipotecóico, que é responsável pela adesão da bactéria à fibronectina do epitélio da orofaringe, iniciando assim a colonização bacteriana. As camadas média e interna são formadas por açúcares e mantém a rigidez e a forma da bactéria.

A proteína M é a proteína mais imunogênica do estreptococo e ainda possue propriedades antifagocitárias. É uma proteína fibrilar, em alfa hélice dupla, e apresenta similaridade com proteínas do tecido humano, como miosina cardíaca, tropomiosina, queratina, vimentina, laminina (3). Recentemente, nosso grupo identificou um grande número de proteínas isoladas da valva mitral reconhecidas por anticorpos e por linfócitos $\mathrm{T}$, mostrando que existe grande diversidade no reconhecimento e que provavelmente estas diferentes proteínas apresentam homologia de sequência e/ou estrutura entre si e com a proteína M (D. Diefenbach da Silva e L. Guilherme, 2001- resultados não publicados) e, conseqüentemente, podem ser alvo de reação cruzada.

O aspecto fibrilar da proteína $M$ também é importante para a fisiopatologia da FR. Proteínas fibrilares só conseguem ter esta forma devido a um arranjo específico de domínios hidrofóbicos e hidrofílicos, e assim admitem poucas variações em sua composição. Por este motivo, estas proteínas têm seqüências bastante conservadas em vários organismos diferentes, o que pode explicar o grande número de homologias entre esta proteína e o tecido humano. Podem-se identificar seqüências e epítopos idênticos entre proteínas do microorganismo e do hospedeiro, como a sequência GIn-Lys-Ser-Lys-Glu, que está presente na tropomiosina, na miosina e na proteína $\mathrm{M}^{3}$

\section{A resposta imune na doença reumática}

A existência de processo auto-imune na FR foi postulada após a observação de que as lesões no coração estavam associadas a anticorpos que reconheciam o tecido cardíaco. Kaplan confirmou essa observação experimentalmente utilizando extratos de parede celular de estreptococo e mostrando que os anti-soros obtidos reconheciam tanto o tecido cardíaco quanto o estreptococo ${ }^{11}$.

O mecanismo atualmente postulado para o desenvolvimento da FR envolve o mimetismo molecular entre proteínas do hospedeiro e do estreptococo. Anticorpos do hospedeiro dirigidos

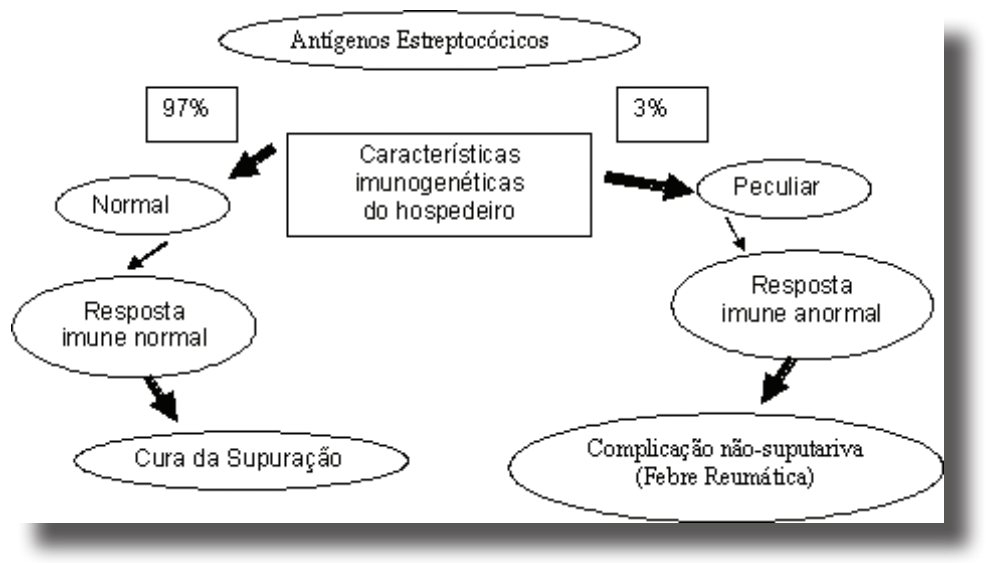


Spina GS. Doença reumática: negligenciada, mas ainda presente e mortal.

contra antígenos estreptocócicos também reconhecem estruturas do hospedeiro, iniciando o processo de auto-imunidade. Assim, como acontece o reconhecimento cruzado humoral, também acontece a reação cruzada celular, com linfócitos $T$ ativados com epítopos estreptocócicos passando a reconhecer epítopos próprios, causando uma agressão celular a tecidos próprios. Esta resposta celular parece ser especialmente importante em pacientes que desenvolvem cardite grave. O papel dos anticorpos na FR parece ser mais importante durante a fase inicial da FR, causando entre outros, artrite por depósito de imunocomplexos nas articulações. Assim, as manifestações de artrite e coréia de Sydenham da FR estariam mais envolvidas com a resposta humoral, enquanto que a cardite grave estaria mais ligada à resposta celular.

Na cardite reumática, não é claro o papel da resposta humoral, sendo possível que ela cause alguma forma de lesão na fase aguda da doença. Estudos histológicos de pacientes com Doença Reumática Cardíaca (DRC) mostraram células plasmáticas cercadas por linfócitos $\mathrm{T} \mathrm{CD} 4^{+}$, próximos a fibroblastos, sugerindo interação entre a célula plasmática (linfócito B) e o linfócito $\mathrm{T}^{12}$. Os nódulos de Aschoff, considerados patognomônicos da doença, são compostos por agregados de células semelhantes a macrófagos e monócitos, que exercem a função de células apresentadoras de antígeno para as células $\mathrm{T}^{13}$. Desta forma, além da reação cruzada inicial, temos uma apresentação continuada de antígenos no sítio da lesão, contribuindo para uma amplificação da resposta imune e ativação de maior número de clones auto-reativos de linfócitos T. A presença de linfócitos T CD4+ em grande quantidade foi demonstrada em pacientes com DRC, o que sugere um papel direto destas células na patologia da doença ${ }^{14}$. O papel funcional destes linfócitos foi demonstrado a partir do isolamento de clones de linfócitos T infiltrantes do tecido cardíaco (miocárdio e valvas), provenientes de pacientes submetidos à cirurgia para correção valvar. Observou-se que eles são capazes de reconhecer tanto antígenos da proteína $\mathrm{M}$ do estreptococo quanto antígenos cardíacos, evidenciando, pela primeira vez, o mimetismo molecular que ocorre entre o tecido cardíaco e o estreptococo, com ativação de linfócitos CD4+ levando a processo de auto-agressão. Os mesmos epítopos da proteína M e as mesmas frações de proteínas infiltrantes são reconhecidos tanto em linfócitos intralesionais como em clones isolados do sangue periférico de pacientes com $\mathrm{FR}^{15,16}$.

Além dos mecanismos descritos, a produção de citocinas influencia de forma decisiva a resposta imune nos pacientes com FR. O número aumentado de linfócitos $\mathrm{CD}^{+}{ }^{+}$no sangue periférico de pacientes com DRC estão ligados a aumento de IL-1, TNF alfa e IL-2 no soro ${ }^{17}$. A análise do perfil de citocinas no tecido cardíaco de pacientes com doença reumática cardíaca grave mostrou predomínio de células mononucleares secretoras de TNF alfa e IFN (padrão Th1) (L. Guilherme e cols, em preparação). Postula-se que a produção de citocinas também direcionaria a resposta imune para uma reposta mais humoral (resposta Th2), que causaria quadro clínico com coréia e artrite, ou para uma resposta mais celular (resposta Th1), causando quadros de cardite grave e seqüela valvar. Esta diferença de resposta é vista também na clínica, pois apenas $5 \%$ dos pacientes com cardite grave cursaram com coréia, enquanto que entre pacientes com cardite leve, 65\% tiveram coréia de Sydenham ${ }^{16}$. Baseado no conjunto destes dados, apresenta-se a seguir um esquema ilustrativo do processo infeccioso pelo $S$. pyogenes levando ao desenvolvimento doença reumática nos indivíduos suscetíveis.

\section{Marcadores genéticos}

Desde o início do século, pesquisa-se marcadores genéticos de suscetibilidade para a FR. Inicialmente, pesquisaram-se a relação dos grupos sangüíneos, e mais tarde o estado secretor e não-secretor. Ambas as pesquisas não mostraram correlação. Na década de 70, com a descoberta do complexo de histocompatibilidade de classe I, pesquisou-se a associação destes marcadores com a FR, e viu-se que também estes marcadores não conseguiam identificar indivíduos mais predispostos à $\mathrm{FR}$.

Mais tarde, Patarroyo et al. ${ }^{18}$, em 1979 identificou o antígeno 883, que estava presente em linfócitos B de $75 \%$ dos pacientes com FR da Colômbia e $80 \%$ dos pacientes com FR dos EUA. Este foi o primeiro marcador de suscetibilidade descrito para a FR. A partir destes dados Zabriskie et al. ${ }^{19}$, em 1985, produziram anticorpos monoclonais contra o antígeno de membrana dos linfócitos B identificado como antígeno 883 e, dentre os anticorpos monoclonais produzidos, o anticorpo monoclonal denominado D8/17, identificava quase $100 \%$ de pacientes com FR e $20 \%$ dos controles, resultado que não foi reprodutível no Brasil.

Posteriormente à descoberta do antígeno 883, foram descritos os antígenos HLA de classe II, na década de 80 , e passou-se a pesquisar a associação destes antígenos com a FR. Os antígenos HLA de classe II também estão presentes nos linfócitos B como o antígeno 883. Este fato levou alguns pesquisadores a questionar se o antígeno 883 não seria na realidade uma molécula de classe 
II (HLA-DR) até então não identificada ${ }^{20}$. A questão permanece em aberto.

Hoje se sabe por estudos populacionais que há uma associação da doença com os antígenos de classe II e que cada população tem seu próprio marcador (HLA-DR) para a suscetibilidade à FR. É possível que exista um gene que confere suscetibilidade à FR muito próximo ou dentro da região DR. Este achado de diferentes marcadores para cada população é corroborado pela observação de que a incidência de FR após faringite estreptocócica é praticamente a mesma em todo o mundo (em torno de 3-4\%), não variando entre populações diferentes. É possível que diferentes cepas de estreptococos estejam envolvidas e que as diversas moléculas HLA de classe II reconheçam peptídeos antigênicos diferentes.

Há um aspecto familiar na doença, entretanto, os mecanismos de herança não seguem padrões clássicos.

\section{Diagnóstico}

A Febre Reumática é doença auto-imune sistêmica, e inclui manifestações neurológicas, cardiovasculares, osteoarticulares e cutâneas. Estas manifestações foram agrupadas por Jones em critérios maiores e critérios menores para o diagnóstico da Doença Reumática em sua fase aguda, sendo que o diagnóstico seria feito se estivessem presentes dois critérios maiores ou um critério maior e dois critérios menores de $\mathrm{FR}^{22}$. Entretanto, mesmo esta classificação pressupõe exceções, como é o caso da Coréia de Sydenham, que isoladamente faz o diagnóstico de FR. Na prática, raramente os critérios de Jones são aplicáveis, principalmente porque são critérios para diagnóstico de febre reumática aguda, mas hoje a maioria dos pacientes procura atenção médica só na fase crônica da doença.

Até hoje não há um exame laboratorial ou por imagem que permita fazer com segurança 0 diagnóstico de FR. Este diagnóstico, ainda hoje, é baseado no quadro clínico e exame físico detalhado e ajudado por exames laboratoriais inespecíficos, que quando casados com a clínica permitem o diagnóstico da FR na maior parte dos casos. Numa era em que cada vez mais recorremos a exames complementares de alto custo em detrimento de uma cautelosa e pormenorizada observação clínica, a Febre Reumática permanece indiscutível bastião da boa história clínica e do exame físico cuidadoso. Diagnosticar um paciente com FR é proceder com o raciocínio clínico clássico, liberto de diretrizes, fluxogramas e de simplificações.

Cumpre ressaltar que o diagnóstico da FR é mais fácil quando da fase aguda. No período de estado da doença, os muitos sinais clínicos e laboratoriais permitem estabelecer o diagnóstico do quadro na maioria dos pacientes. Nesta fase, é importante restringir o uso indiscriminado e precoce de anti-inflamatórios não-humorais, como detalharemos abaixo.

Diagnósticos retrospectivos de FR podem ser extremamente difíceis, especialmente se o quadro clínico foi de artrite pura, com poucas ou nenhuma seqüela cardíaca. Quando nos deparamos com paciente sem qualquer história de FR, mas com seqüelas cardíacas características de FR, como uma estenose mitral ou uma lesão mitro-aórtica, podemos fazer o diagnóstico presumido de FR com razoável segurança, sendo que nesses casos podemos inclusive indicar profilaxia secundária frente a paciente com seqüelas cardíacas muito características de FR.

A coréia é exceção na $F R$, podendo ser facilmente diagnosticada tanto na fase aguda quanto retrospectivamente pelo seu quadro clinico extremamente característico e também por ser doença estigmatizante, que raramente passa desapercebida, desta forma sempre levando o paciente a procurar atenção médica.

É importante notarmos que, em qualquer população, apenas 3 a $4 \%$ dos pacientes com amigdalite estreptocócica podem desenvolver um surto agudo de FR. Desta forma, podemos dizer que para desenvolver FR, o indivíduo tem que além de ter uma amigdalite não tratada, possuir um substrato genético favorável ao desenvolvimento da FR.

Desta forma, para o diagnóstico da FR não basta demonstrarmos que o paciente teve amigdalite estreptocócica, temos que comprovar as reações não-supurativas subseqüentes que caracterizam a FR.

Anti-estreptolisina O ( ASLO ) - Um erro comum no diagnóstico da FR é a supervalorização dos níveis de anti-estreptolisina O ( ASLO ). Muitos pensam que altos níveis deste anticorpo, marcador de contato com estreptococos beta-hemolíticos, seria altamente sugestivo de FR. Entretanto, analisando a Tabela 1, vemos que ao nos depararmos com um paciente com elevados títulos de ASLO, há $97 \%$ de chance de que este paciente não tenha $F R$, não podendo desenvolvê-la por não possuir substrato genético favorável.

É importante lembrar que de acordo com os critérios de Jones, é importante comprovarmos que houve infecção estreptocócica somente após diagnosticarmos um quadro clínico bastante sugestivo de FR. Muitos médicos atuam de forma incorreta, procurando algum quadro clínico de FR 
Spina GS. Doença reumática: negligenciada, mas ainda presente e mortal.

após receberem o resultado de um título elevado de ASLO no sangue. Devemos lembrar que infecções estreptocócias são bastante comuns, ainda mais na faixa de ocorrência da FR, e assim, altos títulos de ASLO são frequentemente encontrados em escolas, sem ter significado clínico algum. Por fim, o ASLO não é exame de atividade inflamatória, como são o VHS ou a proteína $\mathrm{C}$ reativa, e assim, não serve como marcador de atividade da Febre Reumática. Por isso, este exame deve ser solicitado apenas uma vez, e não serve como parâmetro de seguimento de pacientes com FR.

Tabela1. Critérios de Jones

\begin{tabular}{l|l}
\hline Critérios Maiores & Critérios Menores \\
\hline Artrite & Febre \\
Cardite & Artralgia \\
Coréia de Sydenham & Alterações Eletrocardiográficas (aumento do intervalo PR) \\
Nódulos Subcutâneos & Alterações de exames laboratoriais (provas de atividade inflamatória) \\
Eritrema Magninatum & Evidências de estreptococcia anterior \\
\hline
\end{tabular}

\section{Resposta imune e quadro clínico}

Clinicamente, a resposta humoral (Th2) é a que mais determina sinais e sintomas clínicos. Os sintomas mais freqüentes da Doença Reumática, a artrite e coréia de Sydenham são manifestações predominantemente humorais. Geralmente, estas manifestações permitem o diagnóstico mais precoce da Doença Reumática, o que permite que o prognóstico do paciente a longo prazo seja bom, já que pela natureza da resposta humoral, estes pacientes frequentemente tem lesões cardíacas leves, as quais não tendem a progredir se for observada a profilaxia secundária adequada.

Já a resposta celular se traduz em quadro clínico de mais difícil diagnóstico, já que a maioria dos pacientes não tem manifestações clínicas quando da cardite aguda e os nódulos subcutâneos, outra manifestação de resposta celular, são raros. Muitos pacientes que têm resposta predominantemente celular (Th1) têm quadros clínicos frustros, e assim, não tem sua patologia diagnosticada, o que leva a uma maior probabilidade de novos surtos de Doença Reumática, já que o paciente não estará em uso de profilaxia secundária. Assim, além do paciente ter um pior prognóstico em termos de seqüela valvar tanto pela natureza da resposta celular quanto pelo fato de ter um diagnóstico mais difícil, ele permanece mais tempo sem profilaxia secundária. Por este motivo, não é incomum encontrarmos pacientes adultos jovens com lesões cardíacas reumáticas graves e sem história clínica compatível de Doença Reumática.

Assim, teríamos dois tipos básicos de manifestações da DR, uma predominantemente humoral, com manifestações como artrite e coréia e uma predominantemente celular, de diagnóstico mais difícil, que cursa com cardite e, mais raramente, com nódulos subcutâneos. Cabe ressaltar que frequentemente observamos os dois tipos de resposta no mesmo paciente, havendo concomitantemente manifestações humorais, como a artrite, e celulares, como a cardite.

A observação de pacientes que tiveram manifestação de Coréia de Sydenham revelou que a maioria destes tem lesões valvares mais leves que pacientes com DR com outras manifestações. Esta observação é favorável à teoria de que há pacientes em que a manifestação humoral é predominante e, por isso, há menor seqüela cardíaca. Uma explicação alternativa para este fato é que a maioria dos pacientes com Coréia tem o diagnóstico precoce de DR pela severidade das manifestações clínicas, e assim, tem um risco menor de novos surtos de DR. Além disso, Coréia é uma manifestação extremamente desagradável e estigmatizante, e por isso, os pacientes que a desenvolveram geralmente tem uma aderência melhor à profilaxia secundária por temerem recorrência da doença.

Devemos ressaltar que um paciente que em um surto inicial teve uma resposta predominantemente humoral pode em um surto subseqüente desenvolver uma resposta principalmente celular. Há relatos de pacientes que desenvolveram coréia pura em surto inicial e em novo surto desenvolveram cardite grave, ou seja, tiveram um "switch" de resposta. Este fato poderia ser explicado por: 1. exposição a uma variante de proteína $\mathrm{M}$ que inicialmente determina resposta humoral mais acentuada e em surto 
seguinte a exposição a antígenos que determinassem resposta predominantemente celular devido a cepas estreptocócicas diferentes nos dois surtos; 2. em decorrência da resposta imune que inicialmente pode reconhecer epítopos do estreptococo, chamados de dominantes, e que em um novo surto, pela mesma cepa de estreptococo, reconheceria um grande número de epítopos por um mecanismos conhecido como espalhamento de epítopos ("epitope spreading") ${ }^{23}$ que direcionaria a resposta para o tipo Th1 (celular).

Assim, independentemente da manifestação clínica do surto, é importantíssimo que o paciente tenha boa aderência à profilaxia secundária. Um paciente que tem cardite leve pode, em novo surto de DR, desenvolver lesões cardíacas importantes, por exemplo.

\section{QUADRO CLÍNICO}

\section{Manifestações osteoarticulares}

Classicamente, a artrite da FR é descrita como uma poliartrite migratória assimétrica de grandes articulações, com excelente resposta ao ácido acetilsalicílico. Entretanto, este quadro clássico é visto cada vez menos, principalmente pelo uso cada vez mais disseminado e precoce de antinflamatórios, antes mesmo que o diagnóstico de FR esteja estabelecido. A diminuição da frequência do quadro clássico fez com que nos critérios revisados de Jones conste como critério maior artrite e não mais poliatrite migratória. Idealmente, diante de uma criança ou adulto com artrite que pudesse ser suspeita de $\mathrm{FR}$, deveríamos usar apenas analgésicos como o paracetamol, e não antinflamatórios, a fim de que possamos melhor caracterizar a evolução da artrite. Atualmente, na maioria dos casos, observamos um quadro de poliartrite aditiva assimética de grandes articulações, na qual caracteristicamente há pouca dor articular e intensa inflamação.

A artrite da FR surge geralmente de duas a quatro semanas após a estreptococcia, e tem duração também de duas a quatro semanas. Ocasionalmente, a artrite pode surgir mais precocemente, até uma semana após a infecção estreptocócica, o que levou muitos pesquisadores a denominar esta entidade clínica de artrite reativa pós-estreptocócica. Posteriormente, viu-se que muitos pacientes com este quadro evoluiam para cardite, demonstrando que se tratava apenas de uma variante da Doença Reumática.

O quadro típico é de uma artrite de grandes articulações, não necessariamente assimétrica ou migratória, no qual chama a atenção à desproporção entre dor e inflamação, com o paciente geralmente relatando intensa dor em articulação com sinais flogísticos frustros. A evolução é mais rápida em crianças e em adultos, especialmente acima de 25 anos, a artrite pode ser mais crônica, com duração que pode chegar a 8 ou 10 semanas, e de resposta mais difícil a antinflamatórios não-hormonais.

Artrite do adulto - A artrite em pacientes com mais de 20 anos de idade tem características bastante peculiares, com o paciente apresentando intensa dor articular, que freqüentemente impede a deambulação e sinais flogísticos frustros. Estes pacientes têm comumente resposta insatisfatória a antiinflamatórios não-hormonais e necessitam de terapêutica por tempo prolongado, pois a artrite pode persistir por dois ou três meses, tempo bem mais prolongado que a artrite dita "clássica", vista em crianças e adolescentes. Talvez esse quadro clínico exacerbado esteja ligado à reação imune, que se modificaria com a idade do indivíduo. Por suas características atípicas, este diagnóstico só pode ser firmado em pacientes com diagnóstico prévio confirmado de Febre Reumática

Terapêutica. A terapêutica recomendada em crianças e adolescentes com quadro de artrite por febre reumática permanece sendo o Ácido Acetilsalicílico, na dose de 80 a $100 \mathrm{mg} / \mathrm{kg} / \mathrm{dia}$, ou seja, em dose antiinflamatória. A brilhante resposta que se observa após a administração do AAS é uma característica diagnóstica da artrite da FR. A terapêutica deve ser mantida durante três a quatro semanas, com retirada gradual posterior. Já em adultos com a forma da artrite da FR caracterizada por artralgia intensa e poucos sinais flogísticos, devemos inicialmente prescrever antiinflamatórios não-hormonais em dose plena, como o Naproxeno $500 \mathrm{mg}$ duas ou três vezes ao dia. Na ausência de resposta a estes, o que pode ocorrer em pacientes adultos com artrite da Febre Reumática, está indicada a corticoterapia, com Predinisona 1mg/kg/ dia, associada com analgesia, a qual pode até incluir opiáceos por via oral.

É importante salientar que o uso precoce de antiinflamatórios deve ser evitado ao máximo quando tratamos um paciente com artrite de etiologia não definida. De preferência, nos primeiros dias do quadro articular, o paciente deve ser mantido com analgésicos, como o paracetamol, que tem pouco poder antiinflamatório. Durante este período devemos documentar o padrão da artrite (migratório, aditivo, assimétrico) e se ocorre remissão espontânea do quadro. Muitas artrites reativas virais têm duração inferior a 1 semana, desta forma artrites que entram em remissão em período inferior a 7 dias, sem uso 
Spina GS. Doença reumática: negligenciada, mas ainda presente e mortal.

de antiinflamatórios são provavelmente reativas, e assim, provavelmente, não necessitarão de antiinflamatórios e outras investigações, apenas de seguimento clínico.

\section{Manifestações neurológicas}

A manifestação neurológica típica da FR é a Coréia de Sydenham. Esta consiste na tríade: movimentos involuntários, labilidade emocional e hipotonia. De manifestação tipicamente humoral, a Coréia em geral tem início tardio, ocorrendo de 1 a 6 meses após a infecção estreptocócica, motivo pelo qual pacientes com Coréia raramente têm história característica de estreptococcia.

Em geral afeta crianças, predominantemente do sexo feminino, e em adultos afeta quase que exclusivamente mulheres. As manifestações iniciais são relacionadas à irritabilidade e mais tarde notamse os movimentos involuntários e a dificuldade de escrever e de apreender objetos, causada pela hipotonia que acompanha a doença. Em nosso meio, a forma mais comum de Coréia é a hemicoréia, em que os sintomas são restritos a um hemicorpo. Os movimentos coreicos são exacerbados com estresse emocional e desaparecem com o sono.

Uma manobra valiosa em diferenciar a coréia de outros quadros consiste em solicitar em voz firme que o paciente pare de movimentar o membro afetado pela coréia. Se estivermos diante de paciente com coréia, este vai aumentar seu nível de ansiedade frente à solicitação, e dado que os movimentos são involuntários, observaremos uma exacerbação destes. Já, se estivermos diante de outros quadros, especialmente quadros conversivos, é provável que frente a solicitação os movimentos diminuam, os mesmo cessem. Clinicamente, outro aspecto importante é a presença de movimentos involuntários e fasciculação de língua, que na coréia é classicamente relatada como "língua em saco de vermes".

Classicamente, é dito que a Coréia é autolimitada não deixa seqüelas, contudo, observações recentes parecem indicar o contrário. Mulheres que tiveram coréia na infância podem ter recorrência desta sem novo surto de Doença Reumática durante a gestação (Coreia Gravidarum) ou , mais raramente, durante o uso de anticoncepcionais orais. Tal fato sugere que talvez haja seqüela manifestada por uma sensibilização aos estrógenos em núcleos da base.

Outras possíveis seqüelas neurológicas se relacionam com a observação de que pacientes com doença reumática apresentam grande freqüência de diagnóstico de Transtorno Obsessivo-Compulsivo. Tal hipótese ainda encontra-se em investigação, e pode consistir em evidência de seqüelas tardias da coréia de Sydenham.

Há outras manifestações neurológicas que ocorrem após estreptococcias, conhecidas coletivamente como PANDAS, ou seja, transtorno Obcessivo-compulsivo e tiques relacionados a estreptococcia. Ainda não se sabe se PANDAS seria uma entidade isolada ou apenas uma manifestação atípica da coréia da Febre Reumática.

Terapêutica. A coréia em geral é autolimitada, mas seus sintomas são extremamente incapacitantes e estigmatizantes, e requerem terapêutica sintomática imediata. Em casos leves e moderados, iniciamos como Ácido Valpróico ou a Reserpina. A Reserpina tem sido particularmente útil em casos leves, mas tem o inconveniente de necessitar de formulação (não há apresentação comercialmente disponível) e de ocasionar hipotensão postural.

O Haloperidol, embora muito eficiente no controle da sintomatologia, deve ser reservado aos casos mais graves pelo risco de seqüelas tardias por este fármaco, como a discinesia tardia. Em geral nos casos graves inicia-se o Haloperidol na dose de $1 \mathrm{mg}$ ao dia, apenas pela manhã, pois os sintomas remitem a noite. Esta dose pode ser aumentada gradualmente para até $3 \mathrm{mg}$ ao dia pela manhã, dose que controla a coréia na grande maioria dos casos. $O$ paciente deve permanecer com o fármaco na dose em que obter controle clínico por pelo menos dois a três meses, quando então se procede à retirada gradual, com atenção à volta dos sintomas clínicos. Durante o tratamento é de grande importância monitorar sintomas parkinsonianos, que podem surgir com o uso do fármaco, e que podem progredir até impregnação por neurolépticos.

\section{Cardite}

É a mais grave das manifestações da FR, por deixar seqüelas (cardiopatia reumática crônica). Em nosso meio, cada vez mais pacientes têm quadros de cardite assintomáticos ou oligossintomáticos, tornando cada vez mais difícil o diagnóstico da cardite aguda. O fato de a cardite ser uma manifestação predominantemente celular faz com que possa não haver outros sintomas como artrite e/ ou coréia, que são manifestação predominantemente humorais, dificultando assim o reconhecimento da doença. Outras manifestações celulares como os nódulos subcutâneos podem acompanhar a cardite, e por isso, são classicamente marcadores de cardite grave. O uso precoce de antiinflamatórios nãohormonais também pode dificultar o reconhecimento 
da cardite reumática, impedindo seu reconhecimento e tratamento adequados.

Freqüentemente, a cardite aguda reumática é assintomática, e nem por isso é menos grave: muitos pacientes apresentam-se tardiamente com sintomas decorrentes de seqüelas valvares reumáticas, não sabendo relatar sintomatologia compatível com surto agudo reumático. Como o uso de antiinflamatórios hormonais e, principalmente, a instituição precoce da profilaxia secundária podem mudar radicalmente 0 prognóstico destes pacientes, o diagnóstico do surto de cardite aguda se faz de extrema importância.

Hoje podemos dizer que há dois tipos de cardite grave: a cardite considerada grave por ter sintomas de insuficiência cardíaca e a miocardite e a cardite silente na fase aguda, que determinam importantes seqüelas valvares, e só se tornam clinicamente aparentes décadas após o surto agudo.

Pode ser didaticamente dividida em:

Cardite Leve - Paciente com quadro de taquicardia desproporcional à febre, abafamento da primeira bulha, sopros sistólicos regurgitativos discretos em área mitral, aumento do intervalo PR no eletroardiograma (ECG), com área cardíaca normal à radiografia. Na quase totalidade dos casos é assintomática;

Cardite Moderada-Compreende os sintomas da cardite leve acrescidos de pericardite (dor precordial que melhora com a posição genopeitoral, e piora com o decúbito e com a inspiração, acrescida de atrito pericárdico à ausculta). Os sopros em geral são mais intensos e há aumento discreto a moderado da área cardíaca, podendo haver imagem cardíaca sugestiva de derrame pericárdico. O ECG pode revelar prolongamento do intervalo $\mathrm{QT}$, complexos QRS de baixa voltagem e sobrecarga de câmaras esquerdas. A maioria dos pacientes que não apresenta pericardite é assintomática;

Cardite Grave - O principal sintoma da cardite grave é a insuficiência cardíaca. Pode ocorrer já no primeiro surto de FR, mas é mais comum nas recorrências desta. Pode se iniciar de forma inespecífica, com anorexia, astenia, palidez, taquipnéia, principalmente em crianças. Tais sintomas logo são superajuntados àqueles da insuficiência cardíaca, como edema de membros inferiores, ortopnéia, dispnéia paroxística nortuna e hepatomegalia dolorosa.

O exame físico na cardite grave em geral revela taquicardia, sendo característicos os sopros mitrais. Um aumento do volume de sangue proveniente do átrio esquerdo pode também gerar um sopro diastólico, especialmente quando os folhetos mitrais estão espessados, como acontece na Doença Reumática.
Na fase ativa desta doença, observamos hipofonese de $\mathrm{B} 1$, associada a sopro sistólico regurgitativo e sopro diastólico em ruflar sem reforço pré-sistólico (Sopro de Carey-Coombs). A valvulite aguda leva a uma insuficiência mitral aguda, que determina um aumento do volume em átrio esquerdo e aumento do fluxo sangüíneo na diástole atrial, que faz vibrar a valva espessada pelo processo inflamatório agudo. Pelos motivos acima descritos, este sopro é indicativo de valvulite reumática ativa. Diferenciamos este sopro da dupla disfunção mitral estabelecida por não haver hiperfonese de B1, estalido de abertura de mitral ou reforço pré-sistólico no sopro diastólico, além do quadro clínico, que é bastante diferente nas duas patologias. O sopro mais comum na cardite reumática é o sopro sistólico regurgitativo mitral.

O eletrocardiograma pode revelar sobrecarga de câmaras esquerdas, e por vezes arritmias atriais. Um sinal importante neste exame é a presença de bloqueio atrioventricular do primeiro grau, que inclusive é critério menor de Jones para o diagnóstico. A radiografia de tórax em geral apresenta grande aumento da área cardíaca e congestão pulmonar. O ecocardiograma, especialmente o transesofágico, além do espessamento valvar e das insuficiências valvares, pode mostrar as pequenas verrucosidades reumáticas na borda das valvas características de atividade reumática. Outro exame de imagem que pode ser útil nesta fase é a cintilografia cardíaca com Gálio-67, que tem boa especificidade para a miocardite reumática.

Terapêutica. As medidas gerais são muito importantes, como restrição hidrossalina e repouso absoluto, por quatro a seis semanas no caso da cardite leve e moderada e até o controle da insuficiência cardíaca no caso da cardite grave, com retorno gradual às atividades após este período. Embora alguns grupos tenham utilizado antiinflamatórios nãohormonais no tratamento da cardite, entendemos que como mais grave manifestação da doença reumática, a cardite deve ser tratada necessariamente com antiinflamatórios hormonais. Também destacamos que atualmente, como a maioria (mais de $80 \%$ ) dos casos de cardite reumática aguda é assintomática, a identificação de cardite reumática, mesmo que subclínica, demonstra que há grande inflamação miocárdica, que deve ser tratada vigorosamente por sua gravidade. Desta forma, não aconselhamos o uso de antiinflamatórios não-hormonais para o tratamento da cardite.

O antiinflamatório de escolha é a Predinisona, na dose de $1 \mathrm{mg} / \mathrm{kg}$ ara os casos leves e $2 \mathrm{mg} / \mathrm{kg}$ em casos graves, máximo de $60 \mathrm{mg} / \mathrm{dia}$, com uma dose por dia, pela manhã. Em pacientes com insuficiência 
cardíaca de difícil controle, está indicada a pulsoterapia com Metilpredinisolona, na dose de $1 \mathrm{~g}$ por três dias consecutivos (diluído em soro e administrado lentamente), podendo ser repetida até quatro vezes. Em crianças, a dose é de 10 a $40 \mathrm{mg} / \mathrm{kg}$ de Metilpredinisolona, e após a pulsoterapia os pacientes devem continuar com corticoterapia oral. Os corticóides devem ser mantidos por três a quatro semanas em dose máxima, quando então deve ser feita a retirada gradual, em média de $20 \%$ por semana, não sendo necessária, em nossa experiência, associação de AAS na retirada do corticóide. A duração da corticoterapia pode ser guiada por parâmetros clínicos, como a taquicardia (o mais sensível marcador clínico de atividade reumática) ou o grau de insuficiência cardíaca. Parâmetros laboratoriais como mucoproteínas, alfa-1 glicoproteína ácida e fração alfa-2 da eletroforese de proteínas também devem ser usados para acompanhamento da terapêutica.

\section{Manifestações cutâneas}

As manifestações cutâneas da FR são bastante raras em nosso meio, embora sejam bastante características da doença. Os nódulos subcutâneos são formações com diâmetro médio de $1 \mathrm{~cm}$ que surgem em superfícies extensoras, sobre tensões e em couro cabeludo, sendo manifestações celulares, são marcadores de cardite grave.

O eritema marginatum é manifestação raríssima em nosso meio, de fundo humoral, e caracterizado por máculas róseas, confluentes com bordas eritematosas e centro claro, em regressão. São confluentes, não pruriginosas e sem descamação, motivos pelos quais raramente são percebidos pelo paciente. Em geral, ocorre em tronco e raiz de membros (chamada classicamente de região de "traje de banho") (Figuras 1, 2 e 3).
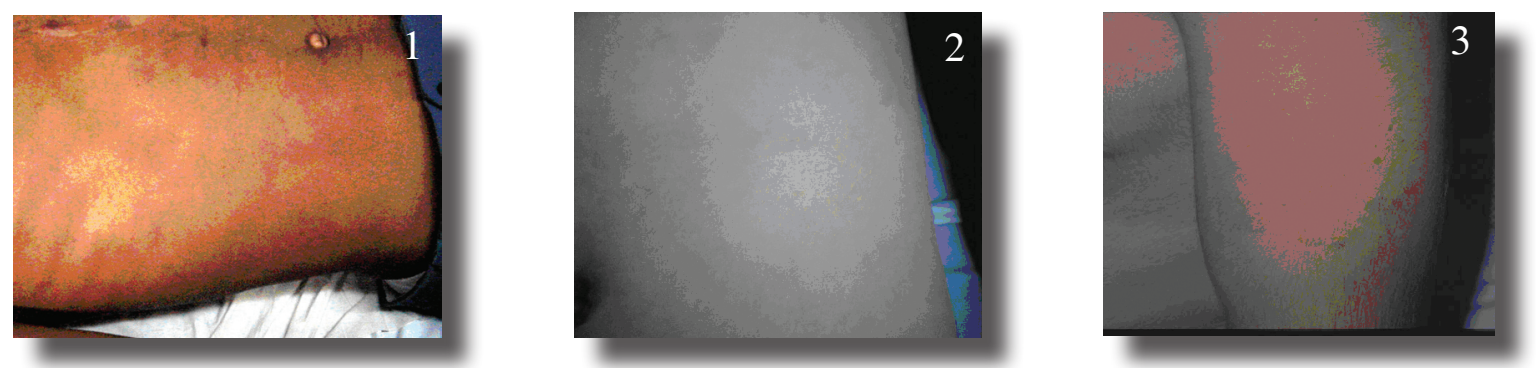

Figuras 1, 2 e 3. Eritema marginado. Cortesia da Liga de Combate à Febre Reumática da FMUSP

Nenhuma das manifestações cutâneas da FR requer tratamento específico.

\section{Profilaxia primária da FR}

Para impedir que novos casos continuem surgindo, o mais importante é realizar adequadamente a profilaxia primária da $\mathrm{FR}$, impedindo que os indivíduos suscetíveis venham a contrair a doença. Infecções (faringites e amigdalites) por estreptococos beta-hemolíticos do grupo A não diagnosticadas e não tratadas adequadamente, em indivíduos sensíveis podem levar a um surto de FR. Assim, é necessário um esquema eficaz não só de tratamento mas de prevenção de infecções pelos estreptococos.

Alguns autores têm questionado a utilidade e custo-efetividade da profilaxia primária. Estes autores argumentam que a profilaxia primária, com a realização de testes como o teste rápido de orofaringe para a detecção de estreptococos, é cara e pouco efetiva. Por este motivo, estes autores postulam que deveria ser feita uma triagem populacional com vistas à detecção de pacientes com cardite reumática subclínica e apenas realizar a profilaxia secundária nestes pacientes. A detecção de pacientes com cardite subclínica, segundo estes autores, seria feita com a realização de ecocardiogramas em grande número de crianças, como em escolas, a procura de lesões características de FR, para então prescrever a estes pacientes profilaxia secundária.

Entretanto, não achamos ser esta conduta a mais adequada ou custo-efetiva. Além do alto custo e dificuldade logística de realizar um grande número de ecocardiogramas, a abordagem sugerida de não realizar a profilaxia primária deixa de prevenir as formas graves da Febre Reumática, como a cardite reumática grave, que pode até ser fatal.

Devemos lembrar que fatores sócio-econômicos estão relacionados a estas infecções e, portanto, a casos de FR. A FR classicamente é considerada uma doença derivada de más condições de vida da população, aglomerações e de um sistema de saúde que não consegue dar à população assistência adequada. Assim, o adequado tratamento das infecções estreptocócicas passa pela melhora das condições 
de vida da população, especialmente aquelas de mais baixa renda, que por viver em condições favoráveis a disseminação dos estreptococos (precárias condições de higiene, aglomerações e maior promiscuidade) e sem acesso ao sistema de saúde é a mais suscetível à FR. Um dos fatores que levaram ao declínio da FR na Europa e América do Norte foi a melhoria das condições de vida da população, combinada a um adequado sistema de tratamento de infecções estreptocócicas, com identificação e tratamento precoce dos portadores de amigdalites estreptocócicas. Se todos os casos de amigdalites estreptocócicas pudessem ser adequadamente tratados, poderia se esperar praticamente a erradicação da doença.

A profilaxia primária pressupõe a erradicação precoce da infecção de orofaringe por estreptococos beta-hemolíticos do grupo $\mathrm{A}$, assim prevenindo 0 aparecimento da FR. A profilaxia primária é baseada no diagnóstico precoce dos portadores de infecções estreptocócicas de orofaringe e seu tratamento com antibióticos bactericidas. $O$ diagnóstico rápido é essencial, devendo a infecção ser tratada nos primeiros dias do quadro, pois a persistência do microrganismo por mais de uma semana acarretará, nos indivíduos suscetíveis, a seqüência de reações imunológicas que irá provocar o surto de Febre Reumática.

O quadro clínico da amigdalite estreptocócica inclui dor de garganta, por vezes intensa, impedindo a deglutição, febre alta (acima de $38^{\circ} \mathrm{C}$ ), adenopatia cervical e submandibular e petéquias em palato e úvula. Geralmente não há secreção nasal ou tosse, sendo o diferencial feito com outras infecções das vias aéreas superiores, como as causadas por vírus. Podem ser realizados exames laboratoriais para o diagnóstico da estreptococcia, como a cultura de orofaringe, que em geral tem baixa positividade, e os testes rápidos. Esses testes muitas vezes são de difícil obtenção e retardariam o tratamento adequado da estreptococcia, motivo pelo qual, em geral, em saúde pública o procedimento mais adequado é tratar com antibióticos todas as infecções de garganta com a mínima possibilidade de serem bacterianas. Esse regime mais agressivo de uso de antibióticos é adequado a situações de alta prevalência de estreptococos no ambiente ou em surtos epidêmicos de amigdalite aguda ${ }^{24}$.

O antibiótico de eleição para a profilaxia primária da Febre Reumática é a penicilina G benzatina em dose única de 600.000 UI para crianças de até $25 \mathrm{Kg}$ e 1.200 .000 UI para pacientes acima deste peso, em injeção intramuscular profunda, em dose única. A grande vantagem desse regime é o seu baixo custo, grande eficácia e a não necessidade de se repetir o tratamento. Considerando-se o tratamento por via oral, a droga de escolha ainda é a Fenoximetilpenicilina (penicilina $\mathrm{V}$ ), na dose de 500.000 UI de 12 em 12 horas para crianças e em intervalo mais freqüente de 8 em 8 ou de 6 em 6 horas para adultos ${ }^{25,26}$. Devemos lembrar que o tratamento antibiótico deve ser mantido por pelo menos 10 dias para que possamos prevenir a ocorrência de Febre Reumática. Devemos lembrar que as penicilinas ocupam lugar de destaque no combate às estreptococcias também pela ausência de resistência destes a estas drogas. Novos tratamentos para a amigdalite, como por exemplo com Macrolídeos ou Cefalosporinas podem ser efetivos na erradicação do estreptococo, mas por serem medicamentos de alto custo têm seu emprego limitado na amigdalite estreptocócica, principalmente, quando se tem um tratamento tão efetivo e de baixo custo disponível. Para pacientes alérgicos a penicilina pode-se usar a Eritromicina $10-12 \mathrm{mg} / \mathrm{Kg}$ de $8 \mathrm{em} 8$ horas ou $500 \mathrm{mg}$ de 6 em 6 horas, também durante 10 dias. As sulfas são inadequadas para o tratamento das amigdalites estreptocócicas, pois não são bactericidas e, assim, não previnem a FR' ${ }^{1}$.

Devemos aqui ressaltar que o diagnóstico de amigdalite estreptocócica, mesmo que esta cause um aumento nos títulos de anti-estreptolisina O (ASLO) não faz o diagnóstico de Febre Reumática. Para o diagnóstico desta, é necessário um quadro clínico típico compatível, que em geral se instala após a amigdalite, e não durante essa. Em estudos clássicos em populações confinadas em quartéis, verificou-se que após um surto de amigdalites estreptocócicas apenas $3 \%$ dos infectados desenvolveu quadro clínico compatível com FR. Assim, não basta a estreptococcia, o paciente tem que ser suscetível à FR. Ressaltando, portanto, que títulos elevados de ASLO apenas demonstram estreptococcia anterior, não fazem diagnóstico de FR.

\section{Profilaxia secundária da FR}

Para pacientes que já tem o diagnóstico de Febre Reumática, é indicada a profilaxia secundária para a prevenção de novos surtos de FR. Aqui devemos ressaltar que o diagnóstico correto da patologia é fundamental, e a melhor ferramenta para fazê-lo é a história clínica detalhada do paciente e um exame físico minucioso. Tal cuidado é fundamental para evitar que, por exemplo, pacientes sem FR recebam profilaxia apenas por serem portadores de altos títulos de anti-estreptolisina $\mathrm{O}$ e que pacientes com valvopatia grave não recebam a adequada profilaxia, responsável pela melhora do prognóstico do paciente a longo prazo. 
Spina GS. Doença reumática: negligenciada, mas ainda presente e mortal.

A droga de escolha é a penicilina G benzatina, nas mesmas doses de 600.000 UI para crianças com até $25 \mathrm{~kg}$ e 1.200.000 UI acima deste peso. A frequência das doses de penicilina é motivo de controvérsia, que vem ganhando mais definição graças a muitos estudos comparando diversos regimes de profilaxia. Segundo a American Heart Association ${ }^{27}$, o uso de aplicações mensais seria adequado, reservando-se as aplicações a cada três semanas para localidades com alta incidência de FR ou de amigdalites estreptocócicas. Entretanto, vários trabalhos mostram que, ao menos fora dos Estados Unidos e Europa, o regime de uma aplicação de penicilina a cada quatro semanas é inadequado ${ }^{28-32}$. Assim em nosso meio, a profilaxia secundária deve ser realizada com aplicações de penicilina $G$ benzatina com intervalo máximo de três semanas. Considerando-se que o maior risco de recorrência da FR ocorre nos dois primeiros anos após o surto reumático, a penicilina deve ser administrada a cada 15 dias nos dois primeiros anos após o surto reumático e depois deverá ser administrada com intervalos de 21 dias $^{32}$. Em nosso meio, pela alta prevalência de FR e de infecções estreptocócicas, não devemos usar aplicações mensais de Penicilina G Benzatina porque não proporcionam proteção adequada aos portadores de doença reumática. Para pacientes com alergia a penicilina, está indicada a Sulfadiazina, na dose de 1g/dia, sendo necessário o controle de possíveis quadros leucopênicos.

Os critérios de suspensão da profilaxia são os seguintes ${ }^{33}$ : Pacientes sem acometimento cardíaco, apenas com manifestação articular ou coréia "pura" - suspender aos 18 anos ou 5 anos após o surto reumático; pacientes com cardite durante o surto agudo que não apresentam seqüelas tardias - suspender aos 25 anos ou dez anos após o último surto reumático; pacientes nos quais a profilaxia é retirada e os sintomas retornam, deverão ter profilaxia mantida por mais 5 anos. Pacientes com acometimento cardíaco, mesmo discreto, deverão ter profilaxia prolongada, de preferência por toda a vida, e quando isso não for possível até a Quarta década ${ }^{2,33}$. Devemos ter cuidado especial com pacientes que tem contato ocupacional freqüente com os estreptococos, como os que trabalham em escolas, creches, estes pacientes devem fazer uso da profilaxia secundária enquanto trabalharem em tais atividades, independentemente da idade.

Desde os primeiros trabalhos sobre a profilaxia, vem sendo incentivada a formação de centros para o acompanhamento da profilaxia secundária da Febre Reumática. Esses centros seguiriam os portadores de Febre Reumática e seriam capazes de fazer pesquisa ativa nos casos de absenteísmo, pois a falta de aderência entre adolescentes e famílias migrantes leva a grande incidência de recidivas.

Em nosso meio, destacamos a atuação da Liga de Combate à Febre Reumática da Faculdade de Medicina da Universidade de São Paulo, criada pelo Prof. Dr. Luiz Venére Décourt apenas alguns anos após os trabalhos que embasaram a profilaxia primária e secundária da FR ${ }^{1}$. Com a atuação de acadêmicos, internos e residentes, esse programa piloto de profilaxia que foi criado em 1956, até hoje continua a assistir os pacientes portadores de Doença Reumática, contando atualmente com 60 acadêmicos e 8 residentes, realizando cerca de 2500 atendimentos ao ano a pacientes com FR.

Tabela 2. Prevenção da Febre Reumática

\begin{tabular}{|c|c|c|c|}
\hline Agente & Dose & Via & Duração \\
\hline \multicolumn{4}{|l|}{ Profilaxia primária } \\
\hline Penicilina $\mathrm{G}$ benzatina & $\begin{array}{l}600.000 \mathrm{IU} \text { para pacientes }<27 \mathrm{~kg} \\
1.200 .000 \text { para pacientes } \geq 27 \mathrm{~kg}\end{array}$ & $\mathrm{IM}$ & Dose única \\
\hline Amoxicilina & $\begin{array}{l}\text { Crianças - 50mg/kg 8/8h por } 10 \text { dias } \\
\text { Adultos - 500mg Vo 8/8h por } 10 \text { dias }\end{array}$ & VO & 10 dias \\
\hline \multicolumn{4}{|c|}{ Para pacientes alérgicos à penicilina } \\
\hline Eritromicina & $\begin{array}{l}\text { Crianças - 40mg/kg/dia 6/6h por } 10 \text { dias } \\
\text { Adultos - 500mg VO 6/6h por } 10 \text { dias }\end{array}$ & VO & 10 dias \\
\hline \multicolumn{4}{|l|}{ Profilaxia secundária } \\
\hline Penicilina G benzatina & 1.200.000Ui a cada 15 ou 21 dias & IM & Vide tabela 3 \\
\hline Penicilina V & $250 \mathrm{mg} 2 \mathrm{x}$ ao dia & VO & Vide tabela 3 \\
\hline \multicolumn{4}{|c|}{ Para pacientes alérgicos à penicilina } \\
\hline Sulfadiazina & $\begin{array}{l}0,5 \mathrm{~g} \text { uma vez ao dia para pacientes }<27 \mathrm{~kg} \\
1 \mathrm{~g} 1 \mathrm{x} \text { ao dia para pacientes }>27 \mathrm{Kg}\end{array}$ & VO & Vide tabela 3 \\
\hline \multicolumn{4}{|c|}{ Para pacientes alérgicos à penicilina e à sulfadiazina } \\
\hline Eritromicina & $250 \mathrm{mg} 2 \mathrm{x}$ ao dia & VO & Vide tabela 3 \\
\hline
\end{tabular}


Tabela 3. Duração da profilaxia antibiótica em pacientes com febre reumática

\begin{tabular}{l|l}
\hline \multicolumn{1}{c|}{ Categoria } & \multicolumn{1}{c}{ Duração } \\
\hline Febre reumática sem cardite & 5 anos ou até os 18 anos, o que for mais longo \\
\hline $\begin{array}{l}\text { Febre reumática com cardite sem seqüela valvar, ou com } \\
\text { seqüela valvar mínima }\end{array}$ & $\begin{array}{l}\text { Pelo menos 10 anos após o último surto ou até os 25 anos, } \\
\text { o que for mais longo }\end{array}$ \\
\hline Febre reumática com cardite e seqüela valvar grave & $\begin{array}{l}\text { Pelo menos até os 40 anos. Algumas vezes pela vida inteira } \\
\text { (exposição ocupacional) }\end{array}$ \\
\hline
\end{tabular}

Spina GS. Rheumatic disease: neglected but still present and deadly. Rev Med (São Paulo). 2008 abr.-jun.;87(2):128-41.

ABSTRACT: Rheumatic fever is a frequent disease in Brazil, and leads to serious long-term consequences, such as chronic rheumatic heart disease. Cardiac surgery due to rheumatic sequelae is quite common, having tragic consequences for the young population. The complex physiopathology and variable onset symptoms make the diagnosis of rheumatic fever a tricky one. The article summarizes the current physiopathology, diagnostic and treatment for the manifestations of rheumatic fever, acute and chronic. Special emphasis on primary prophylaxis is advised, as it prevents the development of the disease.

KEYWORDS: Rheumatic fever/diagnosis. Rheumatic fever/physiopathology. Rheumatic heart disease/complications. Rheumatic heart disease/mortality.

\section{REFERENCIAS}

1. Massel B. Rheumatic fever and streptococcal infection: unraveling the mysteries of a dread disease. Harvard Univ Press: Cambridge; 1997.

2. Tanaka ACS. Febre reumática: critérios diagnósticos e tratamento. In: Timerman A, Cesar LAM, editores. Manual de Cardiologia - Socesp. São Paulo: Atheneu; 2000.

3. Cunningham MW. Pathogenesis of group A streptococcal infections. Clin Microbiol Rev. 2000;13(3):470-511.

4. Fischetti V. Streptococcal M protein. Sci Am. 1991;264(6):32-9.

5. Kujala GA, Doshi H, Brick JE. Rheumatic fever and poststreptococcal glomerulonephritis: a case report (letter). Arthritis Rheum. 1989;32(2):236-9.

6. Podbielski A, Melzer B, Lutticken R. Application of the polimerase chain reaction to study the M-protein (-like) gene family in beta-hemolytic streptococci. Med Microbiol Immunol. 1991;180:213-27.

7. Bhardwaj V, Kumar V, Geysen HM, Sercaz, E. Degenerate recognition of a dissimilar antigenic peptide by mielyn basic protein-reactive $\mathrm{T}$ cells. Implications for thymic education and autoimmunity. J Immunol. 1993;151:5000-10.

8. Tomai M, Kotb M, Majumdar G, Beachey E. Superantigenicity of streptococcal M protein. J Exp Med. 1990;172:359-62.

9. Tomai M, Aelion JA, Dockter ME, Majumdar G, Spinella DG, Kotb M. T cell receptor $\vee$ gene usage by human $T$ cells stimulated with the superantigen streptococcal $M$ protein. J Exp Med. 1991;174:285-8.

10. Guilherme L, Dulphy N, Douay C, Coelho V, CunhaNeto E, Oshiro SE, et al. Molecular evidence for antigen-driven immune responses in cardiac lesions of rheumatic heart disease patients. Int Immunol. 2000;12(7):1063-74.

11. Kaplan $\mathrm{MH}$, Svec $\mathrm{KH}$ : Immunologic relation of streptococcal antibody cross-reactive with heart tissue: association with streptococcal infection, rheumatic fever and glomerulonephritis. J Exp Med. 1964;119: 651-66.

12. Willians RC Jr. Host factors in rheumatic fever and heart disease. Hosp Practice. 1982;125-38.

13. Kemeny E, Grieve T, Marcus R, Sareli P, Zabriskie JB. Identification of mononuclear cells and $T$ cell subsets in rheumatic valvulitis. Clin Immunol Immunopathol. 1989;52:225-37.

14. Raizada V, Williams RC JR, Chopra P, Gopinath N, Prakash K, Sharma KB et al. Tissue distribuition of lymphocytes in rheumatic heart valves as defined by monoclonal anti-T cells antibodies. Am J Med. 1983;74:225-37.

15. Guilherme L, Cunha-Neto E, Coelho V, Snitcowsky $R$, Pillegi $F$, Kalil J. Human infiltrating $T$ cell clones from rheumatic heart disease patients recognize both streptococcal and cardiac proteins. Circulation. 1995;92:415-20.

16. Guilherme L, Oshiro SE, Faé KC, Cunha-Neto E, Renesto $G$, Goldberg AC, et al. $T$ cell reactivty 
Spina GS. Doença reumática: negligenciada, mas ainda presente e mortal.

against streptococcal antigens in the periphery mirrors reactivity of heart infiltrating $T$ lymphocytes in rheumatic heart disease patients. Infect Immunity. 2001;69(9):5345-535.

17. Narin N, Kutukçuler N, Ozyurek R, Bakiler AR, Parlar A, Arcasoy M. Lymphocyte subsets and plasma IL-1 a, IL-2 and TNF-a concentrations in acute rheumatic fever and chronic rheumatic heart disease. Clin Immunol Immunopathol. 1995;77(2):172-6.

18. Patarroyo ME, Winchester RJ, Vejerano A, Gibofsky A, Chalem F, Zabriskie JB, Kunkel HG. Association of a B-cell alloantigen with susceptibility to rheumatic fever. Nature. 1979;278:173-4.

19. Zabriskie JB, Lavenchy D, Willians RC Jr, Fu SM, Yeadon CA, Fotino M et al. Rheumatic fever-associated $B$ cell alloantigens as identified by monoclonal antibodies. Arthritis Rheum. 1985;28(9):1047-105.

20. Ayoub EM. The search for host determinants of susceptibility to rheumatic fever: the missing link. Circulation. 1984;69:197-201.

21. Goldberg AC, Kalil J, Kotb M, Mehra N, SaruhanDiresKenel G, Barbalho TP,, et al. HLA in medicine. In genetic diversity of HLA functional and medical implications. In: Charron D, editor. Proceeding of the twelve International Histocompatibility workshop and Conference. France: EDK Medical and Scientific International Publisher; 1997. p.413-8.

22. Dajani AS, Ayoub E, Bierman FZ, et al. Guidelines for the diagnosis of rheumatic fever: Jones criteria, update. Circulation. 1993;87:302-7.

23. Sercarz EE, Lehmann PV, Ametani A, Benichou G, Miller A, Kamal M. Dominance and crypticity of T cell antigenic determinants. Annu Rev Immunol. 1993;11:729-66.

Recebido para publicação: 01/04/2008

Aceito para publicação: 30/04/2008 